\title{
Necrotizing fasciitis: Diagnosis and management of an occult infective focus
}

\author{
Rajiv Y Chandawarkar MD, Timothy A Jessie MD, Gary A Pennington MD, \\ Mark D Wells MD, A Lawrence Cervino MD
}

RY Chandawarkar, TA Jessie, GA Pennington, MD Wells, AL Cervino. Necrotizing fasciitis: Diagnosis and management of an occult infective focus. Can J Plast Surg 2004;12(3): 149-153.

Necrotizing fasciitis is a life-threatening, fulminant disease that is a
diagnostic and therapeutic challenge. Presenting with a triad of find-
ings including progressive erythema, severe dermatological edema
and severe pain disproportionate to the physical findings, this disease
is a surgical emergency. Delayed diagnosis and surgical debridement
lead to higher mortality. Early extensive surgical debridement, aggres-
sive antibiotic therapy, invasive monitoring and intensive care man-
agement determine the outcome in most cases. In patients who fail to
demonstrate clinical improvement, profound sepsis and its sequela -
systemic inflammatory response - have frequently been implicated. It
is these patients that need to be carefully re-evaluated for 'hidden'
foci of infection that may be the real cause of the patient's decline.
Once detected, these occult foci can be surgically debrided, resulting
in dramatic improvement. Two illustrative cases, one with occult
endo- and panophthalmitis and the other with an unusual involve-
ment of deeper muscle planes and the nodal basin, demonstrate this
point. This consumptive process gathers momentum at an alarming
speed, hence, the treatment must be aggressive and prompt.

Key Words: Debridement; Fulminant; Necrotizing fasciitis; Tissue destruction

\section{La fasciite nécrosante : Le diagnostic et la prise en charge d'un foyer infectieux occulte}

\begin{abstract}
La fasciite nécrosante est une maladie fulminante mettant la vie en danger, sans compter que c'est un défi diagnostique et thérapeutique. Se manifestant par une triade d'observations, y compris un érythème évolutif, un œdème dermatologique grave et une douleur marquée disproportionnée par rapport aux observations physiques, cette maladie est une urgence opératoire. Un retard du diagnostic et du débridement chirurgical entraîne un taux de mortalité plus élevé. Dans la plupart des cas, un débridement chirurgical précoce extensif, une antibiothérapie énergique, une surveillance envahissante et une prise en charge en soins intensifs déterminent l'issue. Chez les patients qui n'affichent pas d'amélioration clinique, une septicémie profonde et ses séquelles (une réponse inflammatoire systémique), se produisent souvent. Ce sont ces patients qui ont besoin d'une réévaluation attentive afin de dépister des foyers « cachés » d'infection qui pourraient être la véritable cause du déclin du patient. Une fois dépisté, ces foyers occultes peuvent faire l'objet d'un débridement chirurgical, ce qui entraîne une amélioration remarquable. Deux cas, l'un accompagné d'endophtalmie et de panophtalmie occultes et l'autre, de l'atteinte inhabituelle des plans musculaires plus profonds et du bassin nodal, démontrent ce point. Ce processus consomptif gagne de la vitesse à un rythme alarmant. C'est pourquoi le traitement doit être rapide et dynamique.
\end{abstract}

Invasive streptococcal infection is a rare disease that is frequently followed by a fatal outcome. It is characterized by a rapidly spreading infective necrosis of the subcutaneous tissue and underlying fascia along the fascial planes. Typically, it spares deeper tissues such as muscles, ligaments and bones. In the head and neck region, only 35 cases have been described (1-4) and mortality is as high as $80 \%$. Often caused by an innocuous infection or trauma, necrotizing fascitis (NF) quickly progresses into a surgical emergency. Prolonged sepsis, compromised upper airway and upper mediastinal extension have been identified as factors posing the greatest risk (5). Physicians, especially dermatological surgeons, plastic surgeons and internists, must become familiar with not only the common manifestations of this disease but also the difficulties posed by occult foci of infection. Delay in diagnosis and management may result in death, disfigurement and permanent functional disability.

Two illustrative patients, one with occult endophthalmic involvement and the other with necrotizing process in the chest wall and axillary nodes, emphasize the need for high index of suspicion. We identify two important factors that impact outcome: the involvement of deeper atypical foci of disease; and the need for aggressive multidisciplinary treatment involving the intensivist, infectious disease service, plastic surgeons, ophthalmologists and ancillary staff such as nutritionists and nurses.

\section{Case 1}

\section{CASE PRESENTATIONS}

A 58-year-old man who worked in a grocery section of a supermarket presented to the emergency room in septic shock secondary to NF of the head and neck region. Starting as an innocuous 'boil' on the face, the redness and swelling rapidly spread over five days to involve the entire left face and periorbital region. The acute process extended onto the upper chest as well (Figures 1A and 1B). Computed tomography $(\mathrm{CT})$ scan of the head and neck region revealed subcutaneous air with diffuse inflammatory changes in the entire subcutaneous region of the left face, neck and upper chest

Division of Plastic Surgery, University of Connecticut Health Center, Farmington, Connecticut, USA; Summa Health System, Akron, Ohio,

USA; Department of Surgery, Northeastern University College of Medicine, Akron, Ohio, USA

Correspondence: Dr Rajiv Y Chandawarkar, Division of Plastic Surgery, University of Connecticut Health Center, 263 Farmington Avenue,

Farmington, Connecticut 06030-1601, USA. Telephone 860-679-4444, fax 860-679-7905, e-mail rchandaw@mdanderson.org 


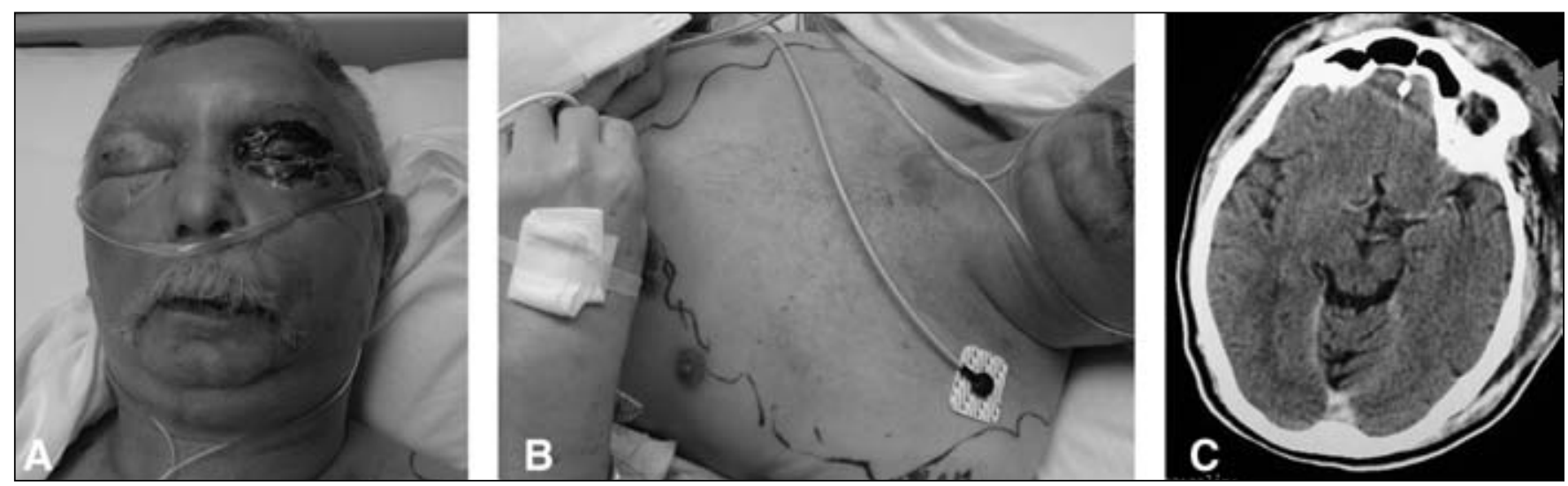

Figure 1) A and B: Preoperative views of the patient as he presented to the emergency room. Note the demarcation of the necrotizing process extending onto the upper chest. C Computed tomography reveals subcutaneous air infiltrating the soft tissues of the face and temporal region

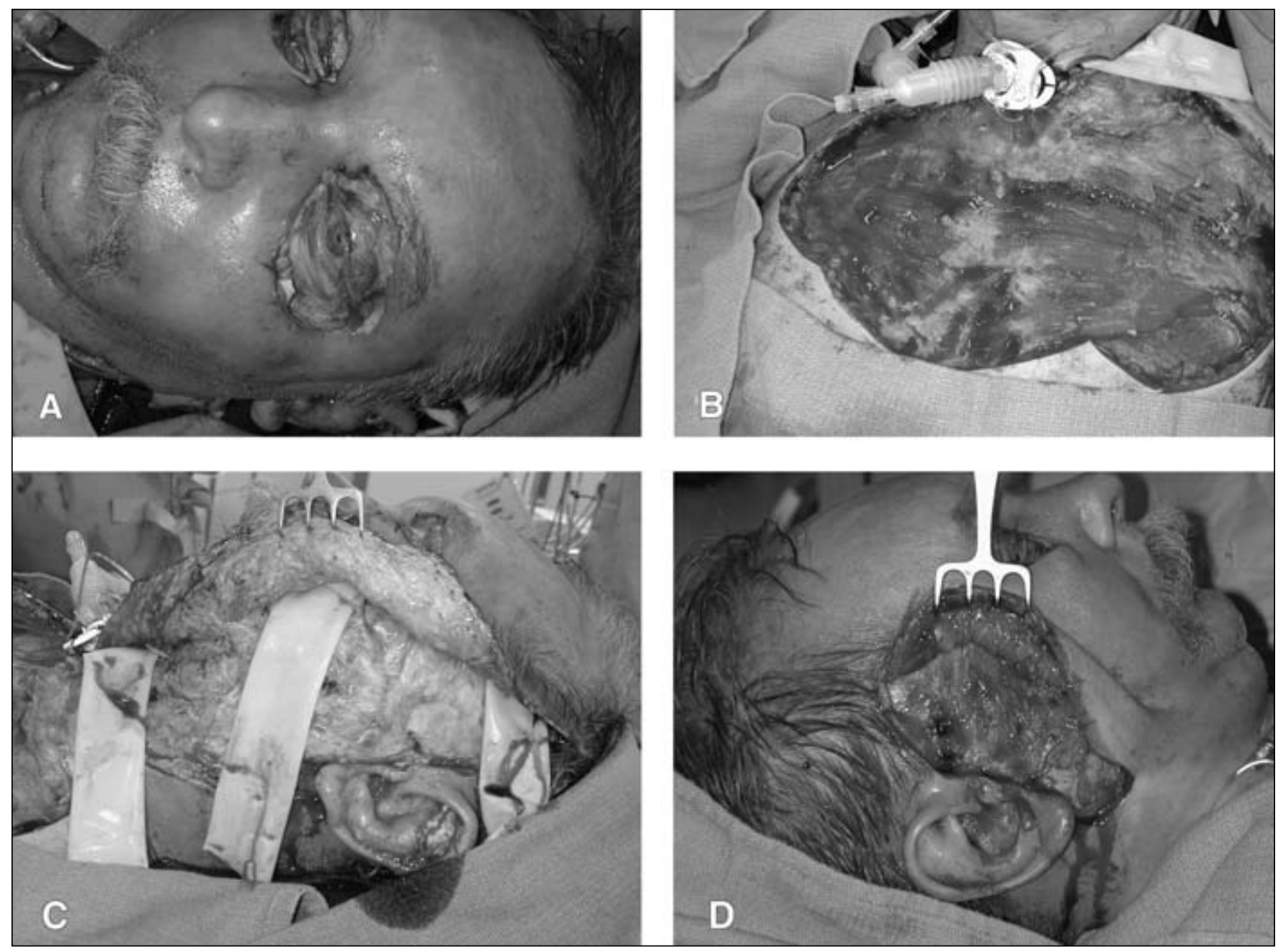

Figure 2) A Involvement of the face and eyelids. B Extent of debridement of chest wall. C Raised facial skin flaps, similar to the facelift flaps, shows involvement of the superficial musculoaponeurotic system (SMAS). D Exploration of the opposite side of the face reveals a normal appearing SMAS

extending over the midline (Figure $1 \mathrm{C}$ ). There was no mediastinal involvement evident on the CT of the thorax or the chest $\mathrm{x}$-ray. After initial evaluation, intravenous clindamycin and aggressive fluid resuscitation, he was taken to the operating room where an emergent tracheostomy was performed to secure his airway after failed attempts at bronchoscopic intubation.
Radical debridement of the face, periorbita, forehead, neck and upper chest was performed (Figures 2A to 2D). Despite aggressive antibiotics, invasive monitoring and other corrective measures, his clinical condition improved very little (Figure 3A) and further debridement was performed using intravenous fluorescein intraoperatively (Figure 3B) by which 

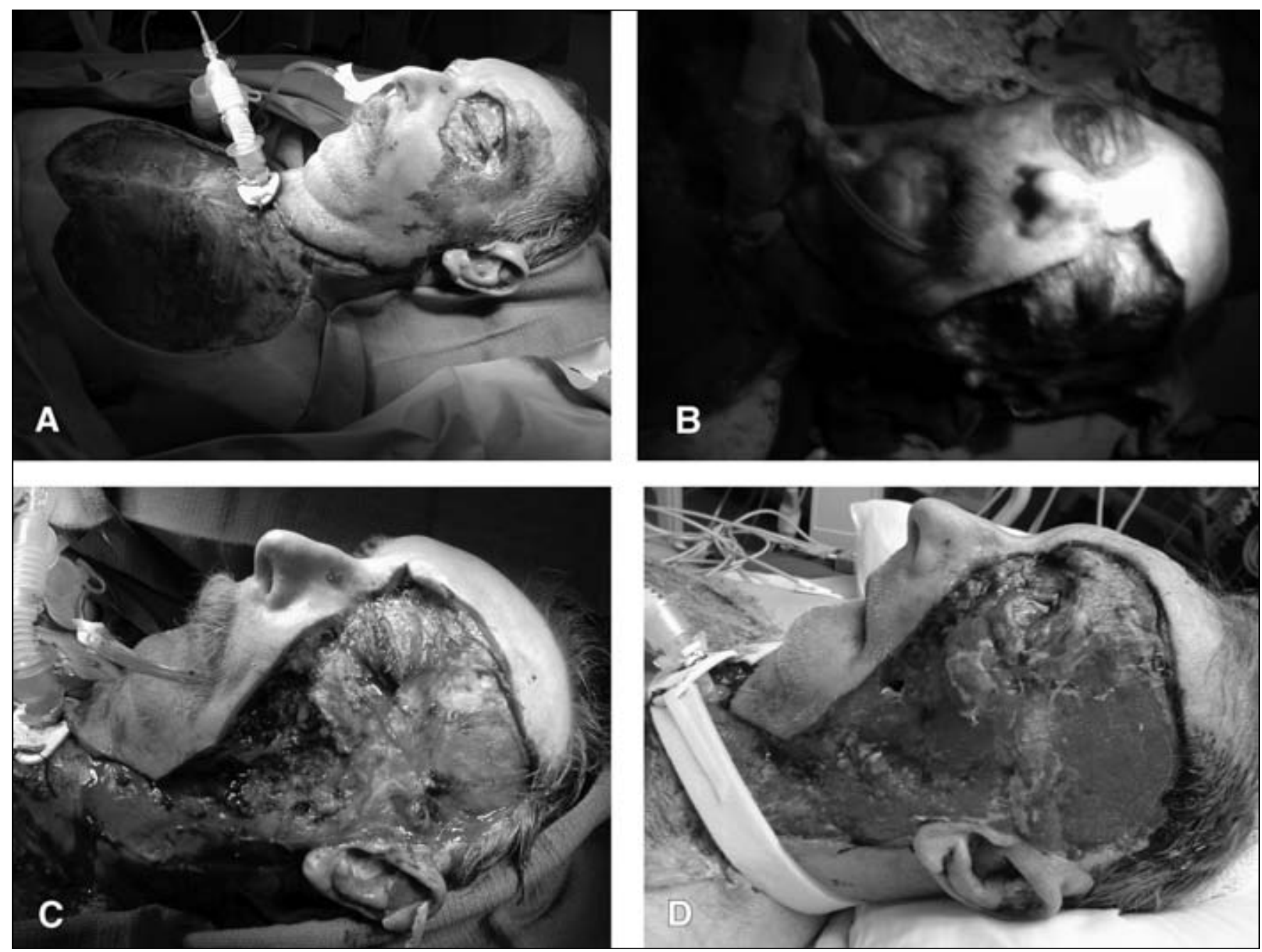

Figure 3) A Continued involvement of the skin and soft tissue of the face. B The use of fluorescein dye intraoperatively (seen under Woods lamp) distinguishes viable and nonviable tissues. C Facial defect before enucleation of the left eyeball and $\mathbf{D}$ after enucleation

ischemic areas were delineated. As seen in Figure 3C, his left face was completely excised.

At that time, the authors began searching for deeper foci of disease in the chest, eyes and skull. Ophthalmic examination revealed left-sided endo- and panophthalmitis. Enucleation was performed promptly and soon thereafter his condition improved dramatically (Figure 3D).

Before reconstruction, his defect included the skin and soft tissue of the entire left face and upper chest and an intraoral communication, shown in Figure 4A (arrow). Subsequent reconstruction involved a free latissimus to his left face and a pedicled latissimus to the neck, followed by skin grafts (Figure 4B). He continued to progress well and was discharged from the hospital on day 31 (Figure 4C).

\section{Case 2}

A 46-year-old previously healthy man presented with a threeday history of left chest pain, diffuse petechiae over his entire body and septic shock. CT revealed a loculated fluid collection in the deep subcutaneous plane of his chest and abdominal wall. Cultures revealed a group A streptococcus infection. Despite extensive debridements of his skin and underlying soft tissue, his clinical conditioned worsened. At this point, during a second operation, a small area of necrosis in the latissimus muscle led to a larger area of involvement deeper to it. A radical excision of the chest wall musculature, including the latissimus, was performed. Dissection proceeded into the axilla where a radical excision of the entire axillary contents up to the level of the axillary vein was performed. After this radical debridment the patient improved, and was later reconstructed with multiple skin grafts. Histology revealed necrotizing lymphadenitis. It is now three years since the patient's initial surgery and he has completely recovered (Figure 5).

\section{DISCUSSION}

First described by Meleny (6) in 1924, NF usually follows an innocuous trauma, bite or abrasion. The porte d'entrée may not be identifiable in most patients. In the head and neck region, dental and pharyngeal infections have been implicated. Common causative pathogens include Streptococcus species and Staphylococcus species such as group A beta hemolytic streptococci, but also Streptococcus viridans, Staphylococcus aureus and Staphylococcus epidermidis (7). The incidence of positive blood cultures is between $25 \%$ and $100 \%$ (8).

Necrosis of the fascial planes is attributed to proteolytic enzymic necrosis of collagen triggered by streptokinase, hyaluronidase and staphylokinase $(2,9)$. Typically, NF involves 

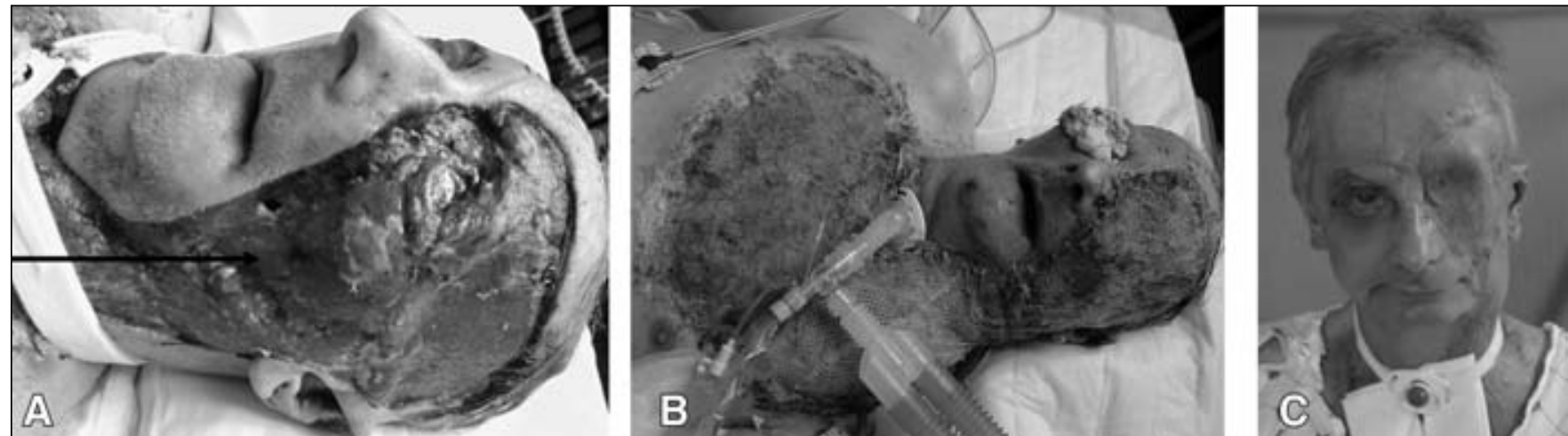

Figure 4) A Defect on face before reconstruction. Arrow marks the intraoral communication. B Post reconstruction with pedicled latissimus dorsi flap to the neck and a free latissimus dorsi flap to the face. C Postoperative view before discharge from the hospital

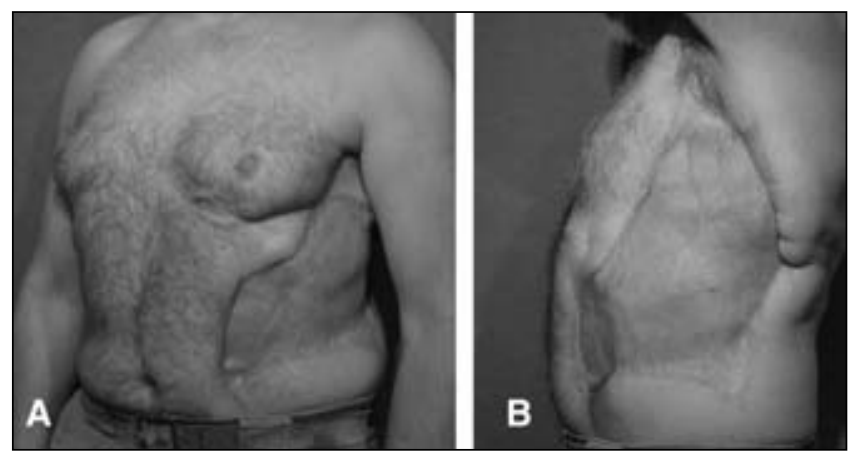

Figure 5) Postoperative pictures of case 2, revealing reconstructed areas on the flank and axilla

the fascia and the layers superficial to it, sparing deeper structures such as muscles, bones, ligaments and tendons. It is unusual for NF to invade deeply, as seen in case 2, where not only was the underlying latissimus involved, but the axillary nodal basin also revealed necrotic lymphadenitis. Diagnostically, the involvement of deeper tissue planes casts a suspicion on the accuracy of the initial diagnosis. However, by careful analysis of the clinical presentation, radiological and pathological findings, cultures and histology, we were able to rule out other diagnoses including bacterial gangrene, pyoderma gangrenosum, purpura fulminans and clostridia myonecrosis.

NF has been divided into distinct groups on the basis of microbiological cultures. Type I infections are polymicrobial, synergistic infections that are usually caused by nongroup A streptococci, aerobic organisms and anaerobic organisms. Type II infections are usually caused by Streptococcus pyogenes alone or with staphylococci. A further type of infection, caused by marine vibrios (Gram-negative rods), is usually associated with seawater or marine animal exposure.

Most patients respond favorably to extensive surgical debridement and antibiotic therapy with clindamycin and penicillin. In addition to its bactericidal action, clindamycin neutralizes toxins, thereby immediately reducing toxemia while having a lasting effect on the bacterial burden. Our surgical approach was aggressive debridment of all infected and nonviable tissue. In the head and neck region, fluorescein was very effective in delineating viable tissue and limited the debridment to its critical areas only (10). In cosmetically sensitive areas such as the face, this approach is very useful and we recommend its wider application.
Both our patients failed initial therapy, even though it was aggressive and involved all the routinely recommended treatment protocols. Evident from our experience is the need for re-evaluating these patients for hidden foci. This vigilance is crucial because the clinical course may quickly take a precipitous downturn and render the situation hopeless. As seen in case 1, endo- and panopthalmitis led to the patient's lack of response to early therapy. It is noteworthy how rapidly he improved after enucleation. Also, as in case 2, excision of the nodal basin and the chest wall musculature proved to be crucial to the patient's prognosis. Had we been complacent in our approach, or attributed the patient's decline to systemic response to sepsis, the outcome may have been different. We do not underestimate the importance of systemic response to sepsis in the prognosis of NF, but we do emphasize the need to thoroughly revisit and re-examine other surgically treatable possibilities.

From literature review, it is important to recognize that $\mathrm{NF}$ is a heterogeneous disease entity $(1-3,11)$. Overall mortality of NF varies greatly, not only based upon the anatomic regions involved but also on the types and numbers of causative organisms. In the head and neck region, NF-related mortality follows two anatomic criteria. Involvement of the upper face, eyelids and scalp has a slightly better survival than those involving the lower face and neck $(6,12,13)$. Reasons for this difference are largely speculative and may be due to the involvement of crucial areas of the head and neck region. Mortality rates of NF involving the trunk largely depend upon the extent of involvement, clinical condition at the time of presentation and the comorbidities that impact the outcome.

Adverse prognostic factors have been summarized by Whetzel et al (4) and include prolonged sepsis (longer than $24 \mathrm{~h}$ ), mediastinal extension, prolonged prothrombin time, underlying diabetes and age over 70 years. Both our patients had prolonged sepsis, which lasted well over $48 \mathrm{~h}$, and one of them had mediastinal extension, diabetes and advanced age. Prothrombin time was prolonged in one patient (case 1) who also had a low calcium level, reflective of sequestration in liquefied necrotic tissue.

Our study strongly recommends the multidisciplinary treatment approach for patients with NF and emphasizes the active input of all components of the team. We worked closely with the intensive care unit team, the infectious diseases service, ophthalmic surgeons, and nursing staff as well as nutritionists, physical therapists and occupational therapists to ensure a good outcome. 


\section{REFERENCES}

1. Sabb PC, Sires BS, Lemke BN, Goldstein JA. Orbital involvement of cervicofacial necrotizing fasciitis. Arch Ophthalmol 1995; 113:1571.

2. Lazow SK. Necrotizing fasciitis and mediastinitis. Atlas Oral Maxillofac Surg Clin North Am 2000;8:101-19.

3. Gates RL, Cocke WM, Rushton TC. Invasive streptococcal infection of the periorbita and forehead. Ann Plast Surg 2001;47:565-7.

4. Whetzel TP, Sykes JM, Reilly DA. Acute reconstruction of massive cervicofacial necrotizing fasciitis with Estlander and free scapular/parascapular flaps. Otolaryngol Head Neck Surg 1999;120:101-4.

5. Sepulveda A, Sastre N. Necrotizing fasciitis of the face and neck. Plast Reconstr Surg 1998;102:814-7.

6. Meleny FL. Hemolytic Streptococcus gangrene. Arch Surg 1924;9:317-63.
7. Beerens AJ, Bauwens LJ, Leemans CR. A fatal case of craniofacial necrotizing fasciitis. Eur Arch Otorhinolaryngol 1999;256:506-9.

8. Buchanan CS. Necrotizing fasciitis due to group A beta-hemolytic streptococci. Arch Dermatol 1970;101:664-8.

9. Shindo ML, Nalbone VP, Dougherty WR. Necrotizing fasciitis of the face. Laryngoscope 1997;107:1071-9.

10. Isenberg JS, Smith K, Tu Q. Necrotizing fasciitis of the periorbita and forehead. J Oral Maxillofac Surg 1997;55:521-3.

11. Nallathambi MN, Ivatury RR, Rohman M, Rao PM, Stahl WM. Craniocervical necrotizing fasciitis: Critical factors in management. Can J Surg 1987;30:61-3.

12. Pal B, Evans S, Walters RF. Necrotising fasciitis of the periorbital region. Eye 2001;15:676-7.

13. Walters R. A fatal case of necrotising fasciitis of the eyelid. Br J Ophthalmol 1988;72:428-31. 